\title{
El arte de la Edad Moderna en Castilla-La Mancha a través de los viajeros
}

\author{
Verónica GıJón JIMÉNEZ \\ Universidad de Castilla-La Mancha \\ Departamento de Historia del Arte \\ veronica.gijon@uclm.es
}

\begin{abstract}
RESUMEN
La literatura de viajes es una fuente importante para estudiar el patrimonio artístico, porque los viajeros solían describir las ciudades y sus edificios. Los relatos de viajes nos proporcionan información desconocida sobre algunas obras de arte y describen monumentos que no se conservan. Los relatos de viaje nos ayudan a conocer cómo eran valorados los edificios en el pasado. He analizado los relatos de sesenta y dos autores, para determinar la contribución que el estudio de estor relatos hace a la Historia del Arte de Castilla-La Mancha.
\end{abstract}

Palabras clave: Literatura de viajes; Historia del Arte; Castilla- La Mancha.

\section{The Art from the Last Decade of the $15^{\text {th }}$ Century to the French Revolution in Castilla-La Mancha through Travelers' Tales}

\begin{abstract}
Travel literature is an important source for the study of artistic heritage as travelers used to describe the cities and their buildings. The travelers' tales provide us with unknown information about some works of art and describe monuments that do not survive. The travelers' tales help us to know how buildings were appreciated in the past. I have analyzed sixty-two authors' tales to determine their contribution to Castilla-La Mancha's Art History.
\end{abstract}

Key words: Travel literature; Art History; Castilla-La Mancha. 
El objetivo principal de este artículo es el estudio del arte de la Edad Moderna en Castilla-La Mancha, utilizando como fuente principal la literatura de viajes. Para ello, he estudiado 62 textos de viajeros extranjeros que describieron el patrimonio de Castilla-La Mancha entre 1495 y $1800^{1}$. Con el análisis de estos relatos de viaje pretendo establecer la clase de viajeros que visitaron Castilla-La Mancha, las razones de su viaje y el espacio temporal en el que se realizaban. Así mismo, identificaré las rutas que seguían dentro de la región, para centrarme en las valoraciones que los viajeros hacían de las ciudades y las obras de arte. También busco determinar los monumentos que fueron analizados con más frecuencia y las razones que llevaron a estos autores a interesarse por ellos. Además había que tener en cuenta las variables que influían en el criterio de los viajeros. Por último, buscaba precisar las aportaciones de la literatura de viajes a la Historia del Arte, en concreto al estudio del arte de Castilla-La Mancha.

\section{El destino de los viajeros}

Hay una serie de factores que influyeron en el número y el tipo de viajeros que visitaban una ciudad, como la importancia política de la misma. En este sentido las ciudades más destacadas de Castilla-La Mancha eran Toledo, que acogió ocasionalmente a la Corte hasta 1651 y era la Sede de la Iglesia Primada de España ${ }^{2}$, Guadalajara, lugar de residencia de los Mendoza ${ }^{3}$; y los arzobispados de Cuenca y Sigüenza ${ }^{4}$. La situación económica y social influye en la impresión que el lugar causaba a los viajeros. Durante el auge económico del siglo XVI las valoraciones fueron positivas, pero durante la crisis del siglo XVII, el deterioro de las ciudades quedó reflejado en los relatos de los viajeros. Esto no cambió en el siglo XVIII, pero en esta ocasión también se hicieron eco de las medidas ilustradas que se tomaron para mejorar la situación económica y cultural del país.

\footnotetext{
1 He decidido realizar este estudio sobre la actual comunidad de Castilla-La Mancha, a pesar de que en la época de la realización de estos viajes no existía como tal. Mi objetivo es estudiar cómo era valorado el patrimonio artístico de la actual región por los viajeros de la Edad Moderna. Es posible que esta demarcación territorial pueda parecer artificial en un estudio sobre la Edad Moderna, pero he optado por esta posibilidad para dar respuesta a la demanda social de estudios histórico-artísticos sobre la actual comunidad autónoma. En cuanto a la división cronológica se refiere, el estudio abarca los relatos de viajes de la Edad Moderna, aunque las fechas indicadas no se ajustas estrictamente a este periodo. El artículo comienza en 1495 porque es el año en el que llega a Castilla-La Mancha Hieronymus Münzer, el primer viajero que visitó estas tierras en la Edad Moderna. El estudio termina en 1800, porque después de 1789 los relatos de viaje no cambian, siguen siendo fruto de la misma mentalidad ilustrada que los escritos antes de esta fecha. Si no se incluyesen estos relatos el estudio quedaría sesgado, ya que le faltarían relatos tan relevantes como el de Wilhelm Von Humboldt o Heinrich Friedrich Link.

2 RODRÍGUEZ DE GRACIA, Hilario, El Toledo que vio Cervantes, Ciudad Real, Almud, 2006, pp. 107-109; DÍEZ DEL CORRAL GARNICA, Rosario, Arquitectura y mecenazgo. La imagen de Toledo en el Renacimiento, Madrid, Alianza, 1987, pp. 217-220.

3 LAYNA SERRANO, Francisco, Historia de Guadalajara y sus Mendozas, vol. I, Guadalajara, Aache, 1994, p. 52.

4 GARCÍA GONZÁLEZ, Francisco, Castilla-La Mancha en la Edad Moderna, Ciudad Real, Almud, 2004, pp. 222-223.
} 
Otro factor importante que determinaba la cantidad de visitantes de una ciudad, eran las vías de comunicación. La única ciudad de Castilla-La Mancha que fue un lugar de destino era Toledo. El resto eran visitadas en función de su proximidad a las vías de comunicaciones. Guadalajara, Sigüenza y las localidades próximas formaban parte de la ruta de Madrid a Zaragoza, La Mancha era frecuentada por aquellos que recorrían el camino de Madrid a Andalucía; y algunas localidades toledanas como Talavera de la Reina, Oropesa, Puente del Arzobispo y Santa Olalla estaban en el camino entre Madrid y Extremadura ${ }^{5}$.

\section{Los viajeros en la Sede Primada y en la provincia de Toledo}

La ciudad de Castilla-La Mancha más visitada en la Edad Moderna fue Toledo. Casi todos los viajeros estudiados la describieron y los que no lo hicieron fue porque tenían un itinerario muy concreto, que no les permitía desviarse. El arquero real Enrique Cock viajaba de Madrid a Zaragoza, Lavagna también viajaba hacia Aragón como cartero real para realizar un mapa de este reino, Cassiano dal Pozzo hacía el camino a la inversa acompañando al cardenal Franceso Barberini ${ }^{6}$. El naturalista alemán Link, el viajero inglés Beckford y el portugués Barreiros viajaron por la ruta de Madrid a Portugal y no consideraron necesario ir a Toledo 7 . El militar inglés destinado en Giblartar, William Dalrymple, hizo la ruta de Andalucía a Madrid, sin pasar por la Sede Primada ${ }^{8}$.

Lo primero que veían los viajeros al llegar a Toledo era su espectacular emplazamiento, asentada en un monte, rodeada por el Tajo por tres de sus lados y fortificada por el lado norte. Münzer ${ }^{9}$, enviado a España y a Portugal por el emperador Maximiliano I, es el primero que hace referencia a esta panorámica y continuarán haciéndolo casi todos los viajeros que escribieron sobre la ciudad. En algunos relatos se describe también el urbanismo, calles muy estrechas con muchas subidas y bajadas y pocos espacios abiertos, con una gran abundancia de edificios religiosos. Los viajeros del

5 SANZ CAMAÑES, Porfirio, "La Mancha en tiempos de Cervantes", en Cuadernos de Historia de España, $\mathrm{n}^{\mathrm{o}}$ 80, 2006, pp. 212-218; OLEA ALVAREZ, Pedro, Los ojos de los demás. Viajes de extranjeros por el antiguo obispado de Sigüenza y actual provincia de Guadalajara, Sigüenza, Rayuela, 1998, pp. XI-XVI.

6 COCK, Enrique, Relación del viaje hecho por Felipe II en 1585 a Zaragoza, Barcelona y Valencia, Madrid, Arribau y Cia, 1976, pp. 13-21; Idem, Jornada de Tarazona hecha por Felipe II en 1592 pasando por Segovia, Valladolid, Palencia, Burgos, Logroño, Pamplona y Tudela, Madrid, imprenta y fundición Tello, 1879, pp. 82-83; LAVANHA, Joao Baptista, Itinerario del Reino de Aragón: por donde anduvo los últimos meses del año 1610 y los primeros del siguiente 1611, Zaragoza, Prames, 2006 (1895), pp. 3-5 y 312-313; DEL POZZO, Cassiano, El diario del viaje a España del cardenal Francesco Barberini escrito por Cassiano del Pozzo, Madrid, Universidad de Navarra, 2004, pp. 55-64.

7 LINK, Heinrich Friedrich, Viaje por España, Madrid, Consejo Superior de Investigaciones Científicas, 2010 (1801), pp. 120-122; BECKFORD, William, Italy with sketches of Spain and Portugal, Paris Bardry's European Lybrary, 1834, pp. 297-300; BARREIROS, Gaspar, Chorographia, Coimbra, Universidad de Coimbra, 1968 (1561), pp. 41-68.

8 DALRYMPLE, William, Travel through Spain and Portugal in 1714 with a short account of the Spanish expedition against Algiers in 1775, London, J. Almon, 1777, pp. 28-35.

9 MÜNZER, Hieronymus, Viaje por España y Portugal (1492-1495), Madrid, Polifemo, 2002, p. 247. 
siglo XVI como los embajadores venecianos Navagero ${ }^{10} \mathrm{o}$ Cavalli ${ }^{11}$ lo tomaron como un rasgo más de la ciudad. A medida que pasa el tiempo se comenzó a ver como una característica negativa. La noble francesa Madame d'Aulnoy ya vio incómoda la estrechez de las calles cuando visitó Toledo en la segunda mitad del siglo XVII ${ }^{12}$. Los viajeros del siglo XVIII como el jerónimo lombardo Caimo, o el viajero inglés Twiss lo mencionaron como un defecto importante ${ }^{13}$. Otro aspecto relevante es el poder que tenía el clero toledano, Navagero es el primero que lo trasmite en su relato y Sobieski nos hace participes de la abundancia de iglesias y conventos que había en la ciudad ${ }^{14}$.

Todos los viajeros que visitaban la Capital Imperial iban a la Catedral; el primer viajero estudiado, Münzer, nos dejó una valiosa descripción del templo toledano, su coro recién terminado, el tesoro y la sillería baja, y el antiguo sagrario ${ }^{15}$. Algunos viajeros se fijarán en otros aspectos de edificio, el cronista de los Reyes Católicos Lucio Sículo hace referencia a sus vidrieras y a las puertas ${ }^{16}$. La capilla mayor y el coro son descritas por muchos viajeros, como Balthasar de Monçonys ${ }^{17}$. En el siglo XVIII, los relieves de Berruguete fueron muy apreciados por autores como el ilustrado francés, Peyron. También ocuparon un lugar importante en los relatos de los viajeros la sacristía y el ochavo una vez estuvieron terminados ${ }^{18}$. El tesoro de la Catedral es descrito por casi todos los viajeros, que solían hacer verdaderos inventarios de las reliquias y las riquezas que contenía, destacando la custodia de Enrique de Arfe, al igual que el ochavo y el sagrario.

Las capillas ocupan un lugar importante en los relatos. Algunos viajeros aludirán a su abundancia y su riqueza, pero sólo describirán detalladamente algunas. Las que más aparecen son la de Reyes Nuevos y Reyes Viejos, la de San Ildefonso y la capilla de la Descensión de la Virgen. La capilla de Santiago es pasada por alto por los primeros visitantes debido a las circunstancias en las que murió su titular. El primer viajero que la menciona es Bertaut en $1659^{19}$. A partir de entonces hablarán de ella otros, porque es una de las más grandes de la Catedral. Destaca la descripción que hace de ella el diplomático Bourgoing, que la vio como un ejemplo de la vanidad de

10 NAVAGERO, Andrea, Viaje por España (1524-15-26), Madrid, Turner, 1983 (1879), p. 110.

11 ALIAGA GIRBÉS, José, "Relación del viaje del embajador veneciano Sigismondo di Cavalli a España (1569)", en Antológica Annua, n 16, 1968, pp. 445-446.

12 D’AULNOY, Marie Catherine, Relación del viaje de España, Madrid, Akal, 1986 (1691), p. 372.

13 CAIMO, Norberto, Lettere d'un vago italiano ad un suo amico, vol. I, Milano, Agnelli, 1758-1759, pp. 136-142; TWISS, Viaje por España en 1773, Madrid, Cátedra, 1999 (1775), pp. 132-133.

14 NAVAGERO, Andrea (1983), op. cit., p. 27; SOBIESKI Jacobo, “El reino de España”, en GARCÍA MERCADAL, José, Viajes de Extranjeros por España y Portugal. Desde los tiempos más remotos hasta comienzos del siglo XX, vol. III, Salamanca, Junta de Castilla y León, 1999, p. 184.

15 MÜNZER, Hieronymus (2002), op. cit., pp. 247-249.

16 SÍCUlO, Lucio Marineo, De las cosas memorables de España, Madrid, La Hoja del Monte, 2004 (1539), p. 52.

17 MONÇONYS, Balthasar, Voyage d'Espagne fait en l'année 1628, Lyon, chez Horace Bissat y George Remeus, 1666, pp. 31-32.

18 PEYRON, Jean François, Nouveau voyage en Espagne, fait en 1777 y 1778, vol. I, London, chez P. Elmsly, 1782 (1780), pp. 329-330.

19 BERTAUT, François, Journal de voyage en Espagne: contenant une description de ses royaumes e de ses principales villes: avec l'estat du gouvernement et plusieurs traites curieux touchant les régences, les assemblées, les commanderies, les bénefices et les conseils, Paris, Chez Louis Billaine, 1669, p. 55. 
las grandezas humanas ${ }^{20}$. La capilla Mozárabe también es visitada por muchos viajeros, pero no se suelen centrar en su arquitectura ni en las pinturas que la decoran, sino en el rito mozárabe.

La sala capitular aparece en los relatos con menos frecuencia, pero los que la describieron, valoraron mucho los retratos de los arzobispos que la adornan. Está presente en el relato de Sículo, en la Floresta Española o en el viaje del heredero del ducado de Toscana, de Cosme de Médicis ${ }^{21}$. El claustro es descrito, sobre todo, por los viajeros del siglo XVIII, como Bourgoing, que hacen referencia a su decoración pictórica. Las descripciones de la colección de pinturas de la Catedral son muy tardías ${ }^{22}$. La primera vez que aparece mencionado un cuadro del Greco es en el relato del viaje de Cosme de Medici ${ }^{23}$, aunque la descripción completa de los cuadros de la Catedral la hace Caimo, utilizando Las Vidas de Palomino. A partir de entonces habrá más autores que hablen de las pinturas de la Catedral, como Peyron o Bourgoing, utilizando para ello el Viaje a España de Ponz ${ }^{24}$. Los artistas más valorados fueron los italianos, como Maratta, Los Bassano o Giordano; pero también se mencionan las obras de Orrente, Carducho o Cajés. El Greco era valorado por tener influencias de Tiziano.

Hay otros elementos de la Catedral que son descritos con menos frecuencia, pero no dejan de ser interesantes por ello. Destacamos la referencia que se hace en la Floresta Española al reloj o al antiguo remate de la torre ${ }^{25}$, la mención del joven viajero francés Monçonys al retablo mayor ${ }^{26} \mathrm{o}$ la valoración del Transparente hecha por algunos viajeros del XVIII. Las opiniones sobre la Catedral suelen ser positivas, todos admiraban sus riquezas y su magnificencia, colocándola entre las mejores de España, incluso de Europa. Bertaut en el siglo XVII y algunos viajeros del XVIII como el ilustrado italiano Baretti, notaron cierto desequilibrio en sus proporciones ${ }^{27}$.

El segundo edificio de Toledo al que se le da más importancia es el Alcázar. Los primeros viajeros que lo visitaron ${ }^{28}$ pudieron verlo cumpliendo la función de residencia real. Entre ellos destaca Antoine de Lalaing, que acompañó a los duques de Borgoña en su primer viaje a España en 1501. Con el traslado de la Corte a Madrid el Alcázar fue perdiendo esta función. Cuando lo vio el diplomático holandés Huygens

20 BOURGOING, Jean François, Nouveau voyage en Espagne ou Tableau de l'Etat Actuel de Cette Monarchie, vol. III, Paris, Chez Regnauld, 1789, pp. 306-307.

21 SÍCULO, Lucio Marineo (2004), op. cit., p. 52; FOULCHÉ-DELBOSC, Richard, "La península Ibérica a principios del siglo XVII", en Revue Hispanique, n 34, 1915, pp. 320-321; MAGALOTTI, Lorenzo, Viaje de Cosme de Médicis por España y Portugal, Madrid, Sucesores de Rivadeneyra, 1933, pp. 150-151.

22 BOURGOING, Jean François (1789), op. cit., vol. III, pp. 309-313.

23 MAGALOTTI, Lorenzo (1933), op. cit., p. 152.

24 CAIMO, Norberto (1758-59), op. cit., vol. III, pp. 19-20; PEYRON, Jean François (1782), op. cit., vol. I, pp. 328-330; BOURGOING, Jean François (1789), op. cit., pp. 208-312; PONZ, Antonio, Viaje de España en el que se da noticia de las cosas más apreciables y dignas de saberse que hay en ella, vol. I, Madrid, Atlas, 1972 (1772), pp. 91-106.

25 FOULCHÉ-DELBOSC, Richard (1915), op. cit., pp. 311-312.

26 MONÇONYS, Balthasar (1666), op. cit, pp. 31-32.

27 BERTAUT, François (1669), op cit., p. 55; BARETTI, Giuseppe, Viaje de Londres a Génova a través de Inglaterra, Portugal, España y Francia, Madrid, Reino de Redonda, 2005 (1830-31), p. 256.

28 LALAING, Antoine, "Voyage de Philippe le Beau en Espagne en 1501", en GACHARD, Luis Prospère, Collection des voyages des souverains des Pays-Bas, Bruxelles, F. Hayez imprimeur de la Commission Royale d'Histoire, 1876, vol. I, p. 179. 
en 1660 hacía las veces de cárcel y Madame d'Aulnoy visitó allí a la reina María Luisa de Orleans y el diplomático François d'Harcourt a Mariana de Neoburgo ${ }^{29}$. Después de la guerra de Sucesión los viajeros describieron sus ruinas tras haber sido incendiado por las tropas del archiduque Carlos. Tras su restauración por iniciativa del cardenal Lorenzana y la fundación de la Casa de Caridad, autores como Townsend nos dan cuenta de la nueva situación de edificio ${ }^{30}$.

Cerca del Alcázar había estado situado el artificio de Juanelo, que servía para abastecer de agua a la ciudad. Navagero nos dio noticias sobre la primera máquina que se construyó con este propósito, pero no era el invento del relojero cremonés. A partir de su construcción en 1565 todos los viajeros lo mencionan, el primero es Cavalli. Aunque fue Monçonys quien consiguió acceder a su interior cuando ya no funcionaba. Su memoria perduró hasta el siglo XVIII, cuando también es reseñado por viajeros como Margarot ${ }^{31}$.

Otro elemento muy presente en los libros de viajes son los hospitales de Toledo. El de Santa Cruz y el de Tavera son los únicos descritos. El primero ya aparece en el relato de Navagero ${ }^{32}$. El segundo es mencionado por el guardia real l'Hermite y visitado por Jouvin, aunque las mejores descripciones se deben a Peyron y Bourgoing ${ }^{33}$. El convento de San Juan de los Reyes está muy presente en los relatos de viajes desde el primer autor estudiado. Precisamente Münzer nos informa de la fecha aproximada de la finalización de las obras y nos da el coste de las mismas. La lista de viajeros que lo mencionan es muy larga y todos tienen una buena opinión del monumento, excepto Magalotti y Peyron ${ }^{34}$. Otros viajeros presenciaron celebraciones importantes que tuvieron lugar aquí, como Lalaing que asistió a los funerales de Arturo de Gales ${ }^{35}$.

El convento de San Pedro Mártir es descrito en menor medida. Destaca el relato de Balthasar de Monçonys, que nos detalla muy bien cómo era el edificio, e incluye elementos como los sepulcros y el retablo mayor de la iglesia ${ }^{36}$. Hay una serie de obras que son descritas por muy pocos autores, como la plaza de Zocodover, los puentes de

29 HUYGENS, Lodewihck, Un holandés en la España de Felipe IV. Diario del viaje de Lodewijck Huygens 1660-1661, Madrid, Doce Calles, 2010, pp. 217-219; D’AULNOY, Marie Catherine (1986), op. cit., pp. 375379; D'HARCOURT, Louis François, “Journal de mon voyage en Espagne. Le $3^{\circ}$ décembre de 1700 jusqu'au $13^{\circ}$ avril1701", en Revue Hispanique, n 18, 1908, pp. 257-258.

30 TOWNSEND, Joseph, Viaje por España en la época de Carlos III (1786-1787), Madrid, Turner, 1988 (1791), pp. 123-124.

31 NAVAGERO, Andrea (1983), op. cit., p. 110; ALIAGA GIRBÉS, José (1968), op. cit., p. 447; MONÇONYS, Balthasar, (1666), op. cit., p. 31; MARGAROT, Maurice, Histoire ou relation d'un voyage qui a duré près de cinq ans: pendant lequel l'auteur a parcouru une partíe de l'Angleterre, la France, l'Espane, le Portugal, vol. II. London, Imprimerie de G. Bigg, 1780, pp. 125-127.

32 NAVAGERO, Andrea (1983), op. cit., p. 29.

33 L'HERMITE, Jehan, El pasatiempo de Jehan l'Hermite. Memorias de un gentilhombre flamenco en la corte de Felipe II y Felipe III, Madrid, Doce Calles, 2005 (1969), pp. 183-184; JOUVIN, Alfred, Le voyageur d'Europe ou sont le voyage d'Espagne et de Portugal et le voyage des Pays-Bas, vol. II, Paris, Chez Louis Billaine, 1672-76, p. 127; PEYRON, Jean François (1782), op. cit, vol. I, pp. 331-338. BOURGOING, Jean François (1789), op. cit., p. 315.

34 MÜNZER, Hieronymus (2002), op. cit., p. 259; MAGALOTTI, Lorenzo (1933), op. cit., p. 156; PEYRON, Jean François (1782), op. cit., vol. I, p. 338.

35 LALAING, Antoine (1876) op. cit., p. 177.

36 MONÇONYS, Balthasar (1666), op. cit, p. 31. 
San Martín y Alcántara, las sinagogas, o los cigarrales. Otros elementos de la ciudad son mencionados con frecuencia, pero nadie los describe. Es el caso de las puertas, las ruinas romanas, el palacio Arzobispal, el Ayuntamiento, el Colegio de las niñas, el hospital del Nuncio Nuevo, la Fábrica de Armas, el castillo de San Servando o la Universidad.

La segunda ciudad más comentada en la provincia de Toledo es Talavera de la Reina; el primero que lo hace es Navagero, que menciona su puente, sus murallas y algunas ruinas romanas. Barreiros además de las murallas, nos da el número de iglesias que había en la ciudad. El noble inglés Bromley nos da el número de conventos y Beckford describe sus edificios y su cerámica ${ }^{37}$. Algunos autores se refieren a Consuegra y el primero que lo hace es Magalotti en el viaje de Cosme de Médicis. Menciona el castillo, la ermita de Nuestra Señora de Finibusterre y el palacio del gran prior de Castilla. El diplomático marroquí Ibn Utman y el ilustrado Wilhelm von Humboldt aluden al castillo y Peyron hace referencia a sus castillos y conventos ${ }^{38}$. Las alusiones a otros lugares de la provincia de Toledo son más aisladas. El cronista real Méndez da Silva cita Ocaña, La Guardia o Puente del Arzobispo; pero solo nos da el número de habitantes, parroquias, conventos y hospitales, además de señalar si tienen muralla, puentes o fortalezas ${ }^{39}$.

El noble francés Bertaut alude al castillo de Guadalerzas, cerca de los Yébenes y al arranque del acueducto de Toledo, Magalotti destaca la limpieza del pueblo de Mora y Twiss describe la fuente Grande de Ocaña ${ }^{40}$. En el siglo XVIII la visión que los viajeros tenían de algunos pueblos de Toledo era muy negativa. Dalrymple afirma que Camuñas era un lugar miserable, y el médico Townsend ve La Guardia al borde de la ruina y solo destaca su iglesia parroquial, al igual que Bourgoing. Por último, hay alguna mención a Illescas y a Tembleque ${ }^{41}$.

37 NAVAGERO, Andrea (1983), op. cit., pp. 30-31; BARREIROS, Gaspar (1968), op. cit., pp. 41-51; BROMLEY, William, Several tears travels through Portugal, Spain, Italy Germany, Russia, Sweden, Denmark and the United Provinces, performed by a gentleman, London, A. Roper, 1702, p. 33; BECKFORD, William (1834), op. cit, p. 298.

38 MAGALOTTI Lorenzo (1933), op. cit., pp. 160-161. VILLAR GARRIDO, Ángel y VILLAR GARRIDO, Jesús, Viajeros por la Historia. Extranjeros en Castilla-La Mancha. Albacete, Junta de Comunidades de Castilla-La Mancha, 2005, pp. 105-108; VON HUMBOLDT, Wilhelm, Diario de Viaje a España. 1799-1800, Madrid, Cátedra, 1998, p. 144.

39 MENDEZ DA SILVA, Rodrigo, Población general de España. Sus trofeos, blasones y conquistas heroicas. Descripciones agradables, grandezas notables, excelencias gloriosas y sucesos memorables con muchas y curiosas noticias, florescogidas en el estimable jardín de la preciosa antigüedad. Reales genealogías y catálogo de dignidades eclesiásticas y seglares. Por Rodrigo Méndes Sylva, coronista de estos reynos. Añadida y enmendada por el mismo en esta última impresión, Madrid, Roque Rico de Miranda, 1675 (1645), pp. 10-17.

40 BERTAUT, François (1669), op. cit., pp. 56-57; MAGALOTTI, Lorenzo (1933), op. cit., p. 158; TWISS, Richard (1999), op. cit., p. 138.

41 DALRYMPLE, William (1777), op. cit., p. 33. TOWNSEND, Joseph (1998), op. cit., p. 255; BOURGOING, Jean François (1789), op. cit., p. 132. 


\section{Viajeros en Guadalajara y su provincia}

La siguiente provincia más visitada es la de Guadalajara, por estar en el camino de Aragón. La mayor parte de los viajeros que la atravesaron se detuvieron en la capital. Las descripciones más completas se dan hasta la segunda mitad del XVII, cuando los duques del Infantado dejaron la ciudad. Destacamos en primer lugar las reseñas que hicieron Münzer y Navagero del palacio del Infantado y las de Cavalli y Münzer del palacio del cardenal Mendoza ${ }^{42}$. Barreiros describe el palacio del Infantado y los jardines. Cock hace referencia a los palacios del Infantado y del cardenal Mendoza, que ya era utilizado como armería. Además nos da el número de parroquias que había en la población y menciona algunos conventos como el de San Francisco y Santo Domingo ${ }^{43}$.

El alemán Cuelbis, además del palacio del Infantado, hace referencia a las murallas, el puente sobre el Henares, el palacio de los marqueses de Montesclaros, el de los condes de Coruña y el convento de San Francisco con el enterramiento de los duques del Infantado ${ }^{44}$. Lavanha también nos da el número de parroquias y conventos y menciona el palacio del Infantado y el panteón de los duques ${ }^{45}$. La descripción que hizo Cassiano dal Pozzo del palacio del Infantado es muy importante, porque describe algunas estancias interiores y los jardines ${ }^{46}$. Guadalajara también está presente en la obra de Méndez da Silva, pero es Magalotti quién más se detiene en su descripción. Menciona el palacio del Infantado, el colegio de jesuitas, la iglesia del convento de las carmelitas y el convento de San Francisco ${ }^{47}$.

El siglo XVIII comienza con la recepción que la ciudad dio a Felipe V y que fue descrita por François d'Harcourt ${ }^{48}$. Su decadencia se hace más evidente, el sacerdote fancés Vayrac afirmaba que Guadalajara es una ciudad mal construida, a excepción del palacio de los duques del Infantado, Saint-Simon solo alude al nuevo panteón que el duque había hecho construir en San Francisco. Caimo describe la fábrica de paños, pero del palacio del Infantado solo le interesan los frescos de Rómulo Cincinato ${ }^{49}$.

Los visitantes de Sigüenza se centraron en la catedral, este es el caso de Münzer, Cavalli y Lavagna, pero tenemos que esperar al relato de Barreiros para ver una des-

42 MÜNZER, Hieronymus (2002), op. cit., pp. 283-285; NAVAGERO, Andrea (1983), op. cit., pp. 23-24; ALIAGA GIRBÉS, José (1968), op. cit., p. 444.

43 BARREIROS, Gaspar (1968), op. cit., p. 64; COCK, Enrique (1876), op. cit., p. 13.

44 CUELBIS, Jacub, Tesoro Chorographico de las Espannas por el señor Diego Cuelbis, obra manuscrita, 1801, fols. 34-35.

45 LAVANHA, Joao Baptista (2006), op. cit., p. 3.

46 DAL POZZO, Cassiano (2004), op. cit., pp. 55-64.

47 MÉNDEZ DA SILVA, Rodrigo (1675), op. cit., pp. 21-22; MAGALOTTI, Lorenzo (1933), op. cit., p. 76.

48 D'HARCOURT, Jean François (1908), op. cit., pp. 253-254.

49 VAYRAC, Jean (1719), État présent de l'Espagne ou l'on voit une géographie historique du pays. L'établisseent de la monarchie, ses révolutions, sa décadence. Par M. l'abbé Vayrac, vol. I, Amsterdam, Chez Steenhouver y Uytwerf, 1719 (1718), pp. 387; DE ROUVROY DUC DE SAINT-SIMONT, Louis, Mémoires complets et authentiques duc de Saint-Simon. Sur le siècle de Louis XIV et la régence. Collationnés sur le manuscrit original par M. Cheruel et précédé d'une notice par $m$. Sainte-Beuve de l'académie française, vol. XIX, Paris, Hachette, 1858 (1788), p. 349; CAIMO (1758-59), op. cit., vol. I, pp. 136-142. 
cripción completa, en la que se incluyen las naves, las torres de la fachada, el claustro, el sepulcro de don Fadrique y el altar de danta Librada. Otros viajeros nos hablaron de otros lugares de la ciudad, Lavanha trata sobre el castillo, el palacio arzobispal, el monasterio de monjes franciscanos, la universidad, el monasterio de carmelitas y el de jerónimos ${ }^{50}$. Méndez da Silva, mencionó las murallas, a las calles de la ciudad y el número de conventos, parroquias y hospitales. Jouvin reseña sus calles principales, la Catedral, el castillo y la universidad. El último viajero es Caimo, que incluye estos monumentos pero los valoró de forma muy negativa ${ }^{51}$. Otros pueblos de la provincia de Guadalajara son frecuentados por los viajeros en menor medida, entre ellos están Hita, Cogolludo, Torija o Brihuega.

\section{La provincia de Cuenca en los relatos de viaje}

Cuenca fue un lugar poco visitado por su aislamiento, pero aún así tenemos algunos testimonios interesantes. Ya Sículo menciona la ciudad, aludiendo a su emplazamiento y a una torre que se levantaba en el castillo, pero el primer relato de viaje donde podemos encontrar una descripción de esta ciudad es la Floresta Española. En este texto también se alude a su emplazamiento sobre un monte escarpado y rodeado por dos ríos. Seguidamente se mencionan algunos de sus edificios más importantes, como la casa de los marqueses de Cañete, la de los condes de Priego, el número de parroquias y conventos con que contaba, y el hospital de Santiago. La Catedral ocupa un lugar importante en esta descripción, que destaca la capilla de los Cañete ${ }^{52}$. Méndez da Silva nos dejó una descripción general de la ciudad, más extensa que las de Janssonius y Coulon que solo trazan un bosquejo de su ubicación ${ }^{53}$.

La mejor descripción se la debemos a Peyron, que de nuevo alude al emplazamiento de la ciudad y hace referencia al puente de San Pablo. Lo que más importancia tiene para él, es la Catedral, de la que destaca los elementos más clasicistas, como el arco de Jamete, el claustro, la capilla mayor o el Transparente. Alaba la custodia de plata, pero no le gustan las proporciones de la Catedral ni la fachada barroca ${ }^{54}$. No hay muchos lugares de la provincia que sean descritos en los libros de viaje; cabe

50 MÜNZER, Hieronymus (2002), op. cit., p. 285; ALIAGA GIRBÉS, José (1968), op. cit., p. 443; LAVANHA, Joao Baptista (2006), op. cit., pp. 312-313; BARREIROS, Gaspar (1968), op. cit., pp. $52-68$.

51 MÉNDEZ DA SILVA, Rodrigo (1675), op. cit., p. 19; JOUVIN, Alfred (1672-76), op. cit., pp. 110-111; CAIMO, Norberto, (1758-59), vol. I, op. cit., pp. 126-143.

52 SíCULO, Lucio Marineo (2004), op. cit., pp. 51-54; FOULCHÉ-DELBOSC, Richard (1915), op. cit., pp. 354-358.

53 MÉNDEZ DA SILVA, Rodrigo (1675), op. cit., pp. 17-18; JANSSONIUS, Johannes, Nuevo atlas o teatro de todo el mundo: en el qual se contienen los mapas y descripciones de España, Asia, África y América, Amsterdam, Johannes Janssonius, 1658-1664, p. 32; COULON, Louis, Le fidele conducteur pour le voyage d'Espagne montrant, exactement les raretez et choses remarquables qui se trouvent en chaques villes, et les distances d'icelles, avec un dénombrement des batailles qui s'y sont donnés par le Sieur Coulon, Paris, Chez Gervais Clouzier, 1654, p. 63.

54 PEYRON, Jean François (1782), op. cit., vol. II, pp. 132-136. 
mencionar la referencia que hacen Cavalli y Bourgoing al monasterio de Uclés y la información que nos da Bronseval sobre el monasterio de Óvila ${ }^{55}$.

\section{Los viajeros en Ciudad Real y Albacete}

Ciudad Real es una provincia muy poco descrita, el primer viajero en mencionar alguna población fue Navagero, que pasó por Almagro, Calatrava la Vieja, Carrión y Malagón, pero prácticamente no nos da ninguna información ${ }^{56}$. Bertaut pasó por la antigua ciudad de Calatrava y por el convento de Calatrava, pero no los describe. Sí lo hace en Almagro, donde visitó la casa del gran maestre, la plaza, la universidad y algunos conventos, entre los que destaca el de las calatravas. También nos dejó la primera reseña del palacio del marqués de Santa Cruz en El Viso y una mención muy breve sobre el recinto de Ciudad Real ${ }^{57}$. Unos seis años más tarde atravesó Ciudad Real Cosme de Medici, su cronista oficial, Magalotti, solo se detuvo a describir Infantes, y nos da información sobre la iglesia de San Andrés, los conventos de Santo Domingo y Santa Clara, y la plaza que había frente a la iglesia ${ }^{58}$.

No encontramos otra relación de una localidad de Ciudad Real hasta el relato de Dalrymple, que habló del palacio del marqués de Santa Cruz, que estaba dañado por el terremoto de Lisboa; menciona también la venta de Manzanares y la de Puerto Lápice ${ }^{59}$. Bourgoing también atravesó La Mancha y es el primero en hablar de la casa de Misericordia que había fundado el cardenal Lorenzana en Ciudad Real ${ }^{60}$. El viajero inglés Townsend mencionó la parroquia, la ermita y el convento de Tembleque, y se interesó por las ventas de Puerto Lápice y Almuradiel, así como el castillo y la iglesia de Manzanares ${ }^{61}$. El último viajero del siglo XVIII que estuvo en La Mancha fue Humboldt, pero tan solo mencionó el castillo de Manzanares y la venta de Puerto Lápice ${ }^{62}$.

La provincia menos atendida por los viajeros es Albacete, el primero que la atravesó fue Brosenval, que alude al castillo de Almansa y pasó también por Chinchi1la, Albacete y La Gineta ${ }^{63}$. El siguiente en viajar por estas tierras fue el embajador Al-Gazzal, pero el único edificio al que hizo referencia es el castillo de Chinchilla, lo mismo ocurre con Ibn Utman ${ }^{64}$. Twiss nos habla, sobre todo, de Albacete, mencionando dos de sus iglesias y la industria cuchillera. La información que nos aporta

55 ALIAGA GIRBÉS, José (1968), op. cit., p. 448; BOURGOING, Jean François (1789), op. cit., vol. III, p. 32; BRONSEVAL, Claude, Viaje por España, 1532-1533: (Peregrinatio Hispanica), Madrid, Centro de Estudios Ramón Areces, 1991, pp. 145-151.

56 NAVAGERO, Andrea (1983), op. cit., ppp. 68-69.

57 BERTAUT, François (1669), op. cit., pp. 61- 62.

58 MAGALOTTI, Lorenzo (1933), op. cit., pp. 164-165.

59 DALRYMPLE, William (1777), op. cit., pp. 29-32.

60 BOURGOING, Jean François, Tableau de l'Espagne moderne, vol. III, Paris, Regnault, 1797 (1789), pp. 30-31.

61 DALRYMPLE, William (1777), op. cit., pp. 33-34.

62 VON HUMBOLDT, Wilhelm (1998), op. cit., p. 144.

63 BRONSEVAL, Claude (1991), op. cit., pp. 139-151.

64 VILLAR GARRIDO, Ángel y VILLAR GARRIDO, Jesús (2005), op. cit., pp. 89-91 y 105-108. 
Bourgoing es más extensa; en Almansa menciona el castillo y describe el monumento conmemorativo de la batalla. También habla de la industria de Albacete, pero del resto de poblaciones apenas dice nada.

\section{Elementos condicionantes de las valoraciones sobre el patrimonio}

Hay una serie de variables que influyen en la configuración de los relatos de viaje y en la valoración que los viajeros hacen de las obras de arte. La primera es el tipo de viajero que escribe el libro. La mayoría de los embajadores no prestan atención a las obras de arte que ven en sus viajes, se interesan por los asuntos políticos y económicos. Algunos consideran necesario hacerlo porque las ciudades que componían un reino eran el reflejo del poder de su soberano. Los cronistas de viajes reales como Cock, l'Hermite o François d'Harcourt, también hacen referencia a los lugares por los que pasan y normalmente llegan a reseñar las ciudades que encuentran en su trayecto. Por último tenemos a los viajeros que visitan un país con la intención de adquirir conocimientos; estos relatos son los que nos aportan una información más valiosa. Aquí podemos englobar a la mayoría de los viajeros ilustrados, como Peyron, Bourgoing, Twiss, Caimo o Baretti, aunque hay casos anteriores; como Sobieski, Balthasar de Monçonys o Cosme de Medici.

La época a la que pertenece cada viajero es un factor determinante a la hora de hacer valoraciones sobre las obras de arte. El período en el que vivió cada uno determina su mentalidad, que influye no solo a la hora de enjuiciar una obra de arte, sino que también determina que el viajero se vea atraído por un elemento concreto o lo ignore. Esto lo podemos ver en distintos casos, como el de las sinagogas de Toledo, que solo son descritos en relatos del siglo XVIII. Los ideales de la Ilustración favorecieron que en este siglo comenzaran a interesarse por ellas. Esto mismo ocurre con las ruinas clásicas, a las que se le da mucha más importancia en el siglo XVIII.

La época también determina el gusto, esto lo podemos comprobar estudiando las valoraciones de la Catedral de Toledo; solo en el siglo XVIII aparecen críticas negativas de viajeros a los que la estructura le parece desproporcionada, entre ellos están Baretti y Humboldt ${ }^{65}$. A Peyron la catedral de Cuenca también le parece desproporcionada, y a la hora de describirla selecciona los elementos más clasicistas, que eran los que estaban más acordes con los gustos de esta época ${ }^{66}$. El gusto de los viajeros también determina que artistas como Berruguete sean muy valorados por viajeros del siglo XVIII, como Caimo ${ }^{67}$.

También debemos a esta razón que los más valorados sean los pintores italianos y que cuando describen cuadros del Greco solo se tiene en cuenta la influencia de Tiziano. Esto se nota también en el desprecio que sentían los autores del XVIII hacia el arte barroco, hecho que se manifiesta en la mención que hace Peyron a la fachada de

65 BARETTI, Giuseppe (2005), op. cit., p. 255; VON HUMBOLDT, Wilhelm (1998), op. cit., pp. 140142.

66 PEYRON, Jean François (1782), op. cit., vol. II, pp. 134-137.

67 CAIMO, Norberto, (1758-59), op. cit., vol. III, p. 21. 
la Catedral de Cuenca, o las valoraciones del Transparente de la Catedral de Toledo ${ }^{68}$. Otro caso en el que se puede ver la influencia de la época en los libros de viaje, es la valoración de las riquezas. En los siglos XVI y XVII lo que más se valoraba de una obra de arte era la riqueza de los materiales, lo cual importaba más que el estilo al que pertenecía. Por este motivo el tesoro de la Catedral de Toledo era admirado por todos los viajeros. Esto cambia en el siglo XVIII, cuando se sorprenden por la riqueza del tesoro, pero opinan que sería más útil si se emplearan en mejorar la economía del país. La época a la que pertenecen los libros de viaje también influye en la extensión de los mismos y la cantidad de datos que nos aportan. Los libros de los viajeros ilustrados nos dan una información muy exhaustiva, en la que se suelen incluir medidas de edificios o inventarios de colecciones de obras de arte, como los que hacen Caimo o Bourgoing de los cuadros de la catedral de Toledo ${ }^{69}$. Esto se debe al afán de los viajeros ilustrados por analizarlo todo y hacer de su viaje algo instructivo para sus lectores.

La procedencia de los viajeros también influye en sus valoraciones, algunos italianos como Navagero, no se fijaron en nuestros monumentos renacentistas, posiblemente porque les parecían insignificantes al lado de los que había en su lugar de procedencia. Otro ejemplo es la valoración que hace Bertaut sobre el palacio del marqués de Santa Cruz, cuando afirma que le parece extraño que los carruajes no pudieran entrar al patio. Esto se debe a que la estructura de los palacios franceses era diferente y el patio tenía la función de acoger a estos vehículos ${ }^{70}$.

La religión del viajero influye mucho en sus percepciones, aunque en la mayoría de los casos la religión viene determinada por el lugar de procedencia. Un caso muy claro de esto son los relatos de los viajeros musulmanes. Al-Gassani vio rastros de su cultura en todas las ciudades de La Mancha por las que pasó. Cuando llegó a Toledo habló de la Catedral como si estuviera en pie la mezquita musulmana y los cristianos le hubieran hecho añadidos ${ }^{71}$. Esto ocurre en menor medida con Al-Gazzal e Ibn Utman, aunque no con el turco Vacif Efendi. También se ve esta influencia de la religión en el caso de los viajeros protestantes ${ }^{72}$. Un caso evidente es el de Twiss, que sentía desprecio por las reliquias y las imágenes de Semana Santa ${ }^{73}$.

El formato del libro que escribe el viajero también tiene que ver con la cantidad y el tipo de información que se proporciona. Los itinerarios como el de Coulon suelen

\footnotetext{
68 PEYRON, Jean François (1782), op. cit., vol. I, p. 328.

69 CAIMO, Norberto, (1758-59), op. cit., vol. III, pp. 19-22; BOURGOING, Jean François (1789), op. cit., vol. III, pp. 208-312.

70 BERTAUT, François (1669), op. cit., pp. 56-57.

71 AL-GASSANI, Abd al Whahab, El viaje del visir para la liberación de los cautivos por el visir Abu Abdel-Lah Mohame Ben Abdeluahab, conocido por el visir El Gassani, el Andalusí; lo presenta, texto árabe y versión Española, Alfredo Bustani, Tánger, Instituto General Franco para la investigación Hispano-Árabe, 1940, pp. 33- 42 y $94-95$.

72 VILLAR GARRIDO, Ángel y VILLAR GARRIDO, Jesús (2005), op. cit., pp. 101-108; BODIN, Marcel "Une rédemption de captifs musulmans en Espagne au XVIIIe siècle (d'après la relation manuscrite d'un envoyé de S. M. le sultan du Maroc)", en Archives Berebères, n 3, 1918, pp. 145-185; EFENDI, Vaçif, "Ambassade de l'historien turc Vaçif Efendi en Espagne (1787-1788)", en Journal Asiatique, nº 19, 1982, pp. 505-523.

73 TWISS, Richard (1999), op. cit., pp. 134-135.
} 
aportar menos información que los libros de viaje propiamente dichos. Esto ocurre también con las descripciones de países como la de Botero ${ }^{74}$, la de Sículo o la de Méndez da Silva.

Un factor a tener en cuenta a la hora de analizar la información que nos aportan los libros de viaje es la intertextualidad. Algunos viajeros describían países que, en realidad, no conocían y extraían los datos de viajeros anteriores y otras obras. Este es el caso de Jouvin, Álvarez de Colmenar ${ }^{75}$-en realidad pseudónimo de un autor anónimo-, el historiador milanés Gregorio Leti ${ }^{76}$, el galés Udal Rhys ${ }^{77}$ o el jesuita valenciano Antonio Conca, expulsado de España con la Compañía de Jesús en 1767. Este último viajero compuso su obra traduciendo al italiano fragmentos completos del viaje de Ponz ${ }^{78}$. También hay viajeros que sí visitaron el país, pero aún así utilizaron relatos anteriores. Entre ellos destacan Madame d'Aulnoy, Jean de Vayrac, el escritor inglés Neville Wyndhan ${ }^{79}$, el abad francés Joseph Delaporte ${ }^{80}$ o Méndez da Silva; aunque este último citaba sus fuentes. Estos relatos nos suelen dar información inexacta y obsoleta, pero hay que tenerlos en cuenta porque en su época tuvieron influencia y ayudaron a construir la imagen de España que tenían en el exterior.

Por último debemos tener en cuenta el papel que juegan las preferencias personales de los viajeros, que determinan que presten atención a asuntos no frecuentes. Un ejemplo claro es el de Navagero, que era aficionado a la jardinería y tenía un jardín en Murano que dejó al cuidado de sus amigos durante su viaje, nos dejó descripciones de todos los jardines que vio en su rayecto, como la Huerta del Rey o la Vega en Toledo ${ }^{81}$. Algo parecido le ocurría a Beckford, que se veía muy atraído por los paisajes. Cosme de Medici era profundamente religioso debido a la educación recibida y por ello visitó muchas iglesias y conventos. Para poder valorar la influencia de las preferencias personales en cada caso, es imprescindible conocer la biografía del autor.

\footnotetext{
74 BOTERO BENES, Giovanni, Relaciones universales: Descripción de España y Portugal, 1595, Madrid, La Hoja del Monte, 2010 (1593).

75 ÁLVAREZ DE COLMENAR, Juan, Les délices de l'Espagne et du Portugal. Oú l'on voit une description exacte des antiquitez, des provinces, des montagnes : de la réligion, des mours des habitans, de leur fêtes : le tout enrichi de figures en taille douce, dessinées sur les lieux mêmes, par Juan Alvarez de Colmenar, 5 vols., Leiden, Chez Pier Van der Aa, 1715 (1707).

76 LETI, Gregorio, Nouvelle relation du royaume d'Espagne. Traduit de l'italien de M. Gregorio Leti, Paris, Chez Simon Boé, 1700 (1699).

77 RHYS, Udal, A tour through Spain and Portugal, \& C. Giving an account of the most remarkable places and curiosities in those kingdoms, London, T. Lownds, 1760 (1750).

78 CONCA, Antonio de, Descrizione odeporica della Spagna in cui spezialmente si da noticia delle cose spettanti alle belle arti degne dell'attenzione del curiosos viaggiatore, Parma, Stamperia Reale, 1793.

79 WYNDHAN, Neville, Travels through Europe: containing a geographical, historical and topographical description of all the empires, kigdong, states drawn from unerring sources of informations... Interspersed with the editors observations... in the course of his own travels by Neville Wyndham, 4 vols., London, H. D. Symerd, 1790.

80 DELAPORTE, Joseph, Le voyageur français, ou la connaissance de l'ancien et du Nouveau monde, vol. XVI, Paris, Chez L. Cellot, 1772.

81 NAVAGERO, Andrea (1983), op. cit., p. 25.
} 


\section{Aportaciones de la literatura de viajes a la Historia del Arte}

Los libros de viaje son una fuente muy valiosa para el estudio de la Historia del Arte. En primer lugar los viajeros describen obras de arte o partes de ellas que ya no existen. En este punto cabe mencionar las descripciones de Münzer y Lalaing del palacio del cardenal Mendoza en Guadalajara o las del antiguo sagrario de la Catedral de Toledo en la Floresta Española y en el relato de Münzer ${ }^{82}$. Barreiros y Cassiano dal Pozzo describen los jardines del palacio del Infantado que no han llegado hasta nuestros días. François d'Harcourt nos reseña las escenografías con las que recibieron a Felipe V en Guadalajara. Otros relatos de viaje nos aportan información sobre determinadas obras de arte, este es el caso del relato de Münzer, que nos traza la finalización de San Juan de los Reyes.

Otra ventaja de los libros de viaje es que sus autores describen las obras de arte cuando aún cumplían la función para la que fueron creadas. Gracias a Lalaing podemos conocer la catedral de Toledo cuando la reina Isabel tenía sus aposentos en el claustro, la iglesia de San Juan de los Reyes cuando acogía celebraciones relacionadas con la monarquía, como el funeral de Arturo de Gales, o el Alcázar de Toledo cuando los reyes celebraban fiestas ${ }^{83}$. Los relatos de Cassiano del Pozzo y Lavanha nos hablan del palacio del Infantado cuando los duques lo habitaban y Bronseval nos transporta al monasterio de Óvila cuando aún acogía una comunidad cisterciense ${ }^{84}$.

Si hacemos un estudio cronológico de los relatos de viaje podemos apreciar cómo evolucionan los monumentos a lo largo del tiempo. Un ejemplo de ello es la catedral de Toledo, cuando Münzer la visitó, hacía poco que se había terminado de cerrar sus bóvedas ${ }^{85}$. Después vemos que se van añadiendo elementos nuevos, como el coro, el retablo, la custodia, la capilla del sagrario y el ochavo o el Transparente de Narciso Tomé.

Al estudiar relatos de autores extranjeros podemos ver cómo se apreciaba nuestro arte en el resto de países europeos; es una información muy útil, si tenemos en cuenta que en el exterior el arte español a penas tenía influencia, ya que el italiano era más valorado. Estudiando los relatos de viaje también podemos observar, por ejemplo, cómo afecta el cambio de gusto que se da en cada época, a la valoración de las obras de arte.

A pesar de que en los siglos XV, XVI y XVII nuestro arte no era conocido fuera de nuestras fronteras, los viajeros que nos visitaron tenían una buena opinión de él. En el siglo XVIII esta tendencia cambia, las opiniones de los viajeros sobre nuestro monumentos son menos positivas. Sin embargo se veían muy atraídos por el arte italiano, lo cual puede ser apreciado al comparar las descripciones de Beckford de las ciudades

82 MÜNZER, Hieronymus (2002), op. cit., pp. 249 y 285; LALAING, Antoine (1876) op. cit., p. 229; FOULCHÉ DELBOSC, Richard (1915), op. cit., pp. 330-336.

83 LALAING, Antoine (1876), op. cit., pp. 174-181.

84 DAL POZZO, Cassiano (2004), op. cit., pp. 55-64; LAVANHA, Joao Baptista (2006), op. cit., p. 3; BRONSEVAL, Claude (1991), op. cit., pp. 145-151.

85 NAVASCUÉS PALACIO, Pedro, La Catedral Primada de Toledo, Madrid, Fundación Cultura y Deporte de Castilla-La Mancha, 2002, pp. 23-24. 
españolas e italianas. La mayoría de los viajeros españoles también compartían esta mentalidad $^{86}$, como se puede ver al analizar el viaje de Moratín a Italia ${ }^{87}$.

Para finalizar es necesario destacar la importancia de la utilización de imágenes de ciudades y obras de arte, contemporáneas a los relatos de viaje estudiados, porque nos ayudan a comprender y ratificar las descripciones de los viajeros, y en algunos casos las complementan. Algunas de ellas están incluidas en los propios libros de viaje, como las acuarelas que el pintor Pier María Baldi compuso para el viaje de Cosme de Médicis o los grabados que aparecen en los libros de los ingleses Twiss y Swinburne ${ }^{88}$ o en el de Alvarez de Colmenar. Hay otras imágenes que también son importantes a la hora de estudiar los textos de los viajeros, como las vistas de Anton van de Wyngaerde ${ }^{89}$, las panorámicas de Cuenca que realizó Llanes de Masa en el siglo XVIII ${ }^{90}$ o los dibujos del Ingeniero Domingo de Aguirre de los pueblos del priorato de San Juan ${ }^{91}$.

86 GARCÍA FELGUERA, María de los Santos, Viajeros, eruditos y artistas. Los europeos ante la pintura española del Siglo de Oro, Madrid, Alianza, 1991, pp. 21-26.

87 FERNÁNDEZ MORATÍN, Leandro, Viaje a Italia, Madrid, Espasa-Calpe, 1991.

88 SWINBURNE, Henry, Picturesque tour through Spain, by Henry Swinburne, embellished with twenty engravings by Walts, Medland, Angus, Mitan, London, J. C. Barnard, 1806 (1779).

89 KAGAN, Richard L., Ciudades del Siglo de Oro, las vistas españolas de Anton Van den Wyngaerde, Madrid, El Viso, 2008.

90 JIMÉNEZ MONTESERÍN, Miguel, Asomarse al pasado. La ciudad de Cuenca en 1773, Cuenca, Ayuntamiento de Cuenca, 1983.

91 AGUIRRE, Domingo de, El gran priorato de San Juan de Jerusalén en Consuegra, en 1769, Toledo, Instituto Provincial de investigaciones y estudios toledanos, 1973. 